http://doi.org/10.35784/iapgos.2429

\title{
NO-CODE APPLICATION DEVELOPMENT ON THE EXAMPLE OF LOGOTEC APP STUDIO PLATFORM
}

\begin{abstract}
Monika Moskal
Silesian University in Katowice, Institute of Sociology, Katowice, Poland

Abstract. Digitalisation is one of the major trends which changes society and businesses. Digitalisation include buying software helping in the automatization of business process. Gaining competitive advantage can be achieved by implementing dedicated (customized) IT solution tailored to the specificity of a given enterprise. However, dedicated solutions are expensive, and many companies cannot afford them. No-code technology - the newest trend in the IT sector - are said to be the solution to this problem. The article discusses why no-code technology is gaining popularity. The paper also presents the differences between no-code and traditional programming approaches. A detailed description of no-code technology was based on the investigation of a no-code platform called Logotec App Studio. The article stresses the possible applications of no-code tools in companies digitalisation process.
\end{abstract}

Keywords: no-code technology, no-code application development platform, Logotec App Studio

\section{TWORZENIE OPROGRAMOWANIA BEZ KODOWANIA NA PRZYKLADZIE PLATFORMY LOGOTEC APP STUDIO}

Streszczenie. Cyfryzacja to jeden z głównych trendów zmieniajacych spoteczeństwo i funkcjonowanie przedsiębiorstw. Cyfryzacja obejmuje zakup oprogramowania pomagajacego $w$ automatyzacji procesów biznesowych. Uzyskanie przewagi konkurencyjnej jest możliwe poprzez wdrażanie dedykowanych (niestandardowych) rozwiazań informatycznych dostosowanych do specyfiki danego przedsiębiorstwa, jednakże ze względu na wysokie koszty pozostaja one poza zasięgiem większości przedsiębiorstw. Technologia no-code-najnowszy trend w branży IT - jest rozwiąaniem tego problemu. $W$ artykule zostały omówione przyczyny, dla których technologia no-code zyskuje na popularności. Przedstawiono również różnice między tradycyjnym podejściem do tworzenia rozwiązan IT, a podejściem no-code. Szczegółowy opis technologii no-code został oparty na badaniu platformy no-code o nazwie Logotec App Studio. W artykule podkréślono możliwości zastosowania narzędzi no-code w procesie cyfryzacji przedsiębiorstw.

Słowa kluczowe: technologia no-code, platforma do tworzenia aplikacji bez kodowania, Logotec App Studio

\section{Introduction}

In today's world, large amounts of data are processed and stored every day [7]. Digitalization is one of the major trends which changes society and businesses. The process of digitalization causes changes for businesses due to the adoption of digital technologies in the organization or in its' environment [15]. According to literature, the process digital transformation refers to "the changes associated with the application of digital technology in all aspects of human society" [17]. According to Keiss and Brennen [3], digitalization is "the adoption or increase in the use of digital or computer technology by an organization, industry, country, etc.”. Digitalization may include turning existing products or services into their digital variants [8] or buying software helping in the automatization of business process. Gaining competitive advantage can be achieved by implementing dedicated IT solutions tailored to the specificity of a given enterprise. However, dedicated solutions are expensive, and many companies cannot afford them. No-code and low-cod application development platforms are said to be the solution to this problem. Both are said to be disruptive technologies which will change the process of application development. For instance, according to Gartner, the leading technology research and advisory company [6] "by 2024, three-quarters of large enterprises will be using at least four low-code development tools for both IT application development and citizen development initiatives" [18]. The current study investigates the possibilities, advantages and potential disadvantages of no-code technology based on the example of Logotec App Studio - no-code application development platform.

\section{No-code - the future of application development}

\subsection{No-code and low-code programming differences}

In the beginning, it is important to make a distinction between low-code and no-code development platforms, which can seem unclear due to the varying nature of platforms' functionalities [2] and the terminology which might be misleading. Low-code programming has become the fourth generation of programming languages. It is also called declarative programming. In this programming approach, it is possible to create IT solutions without extensive programming knowledge when comparing it with the traditional programming approach [1]. However, programming language knowledge is necessary to use low-code development platforms. In contrast, no-code approach does not require any programming knowledge, but the ability of logical and abstract thinking is necessary to create software solutions without coding. The core design of the software solutions in no-code approach is made by the developer through drag and drop manipulation. However, low-code platforms make the creator to be more dependent on the hard core for dictating the application's core architecture. [5] There are many no-code and low-code tools on the market which differ widely in their functionality. However, there is a clear trend: there is a disappearing distinction between tools simple enough for citizen developers and adequately powerful for professional development teams. Therefore, no-code and low-code will combine into a single marketplace segment [2].

\subsection{No-code platforms - the solution for a software crisis}

The introduction to almost every text on software development or software engineering starts with a Software Crisis description. In general, the criticisms are that software projects are over budget, incorrect, late and do not do what they intended [4, 9, 10]. According to Molyneux [13], similar problems arise in order, broader areas of IT or implementing and designing software systems. The reasons why no-code application development platforms gain popularity can be divided into four main aspects: the scarcity of qualified programmers, continuously changing technologies and the need to learn them, high costs, timeconsuming and complicated process of software development. The first reason why no-code is gaining popularity is the scarcity of qualified programmers which hinders the rapid implementation of the project. For a long time, it has been noticed that a large number of students find their (first, second, and third) contact with computing and programming daunting. According to Knuth [10], many programming teachers have observed that only a very small percentage of students really "resonate" with the subject. Finding a qualified (or high-class) programmer does not guarantee 
a project's success. The programmers and software engineering while producing quality software often encounter other problems, for example, how to produce the software within the budget, which is a difficult task [13]. No-code tools, on the other hand, as they do not require programming knowledge, can be used by anyone capable of algorithmic thinking. Therefore, no-code platforms can not only be used by programmers to speed up the process of software development but also by citizen developers, business analysts, consultants, or solutions designers to create business applications without a line of code, resolving the problem of scarcity of qualified programmers on the market. Second, continuously changing technologies and the need to learn them is another factor which causes the rise of no-code popularity. Developers learn a chosen programming language which, apart from long years of studying, often requires many years of practice before one can create advanced IT software. A technological switch also requires a long learning process and many hours of practice which for some may be discouraging. Therefore, only a few of qualified programmers can switch to another programming technology. Third, developing IT solutions using traditional approaches requires large financial outlays. Even system engineers or software engineers notice that developing quality software within set budget is a very difficult activity [13]. However, nocode offers solutions at an incomparably lower cost which will be discussed later in the article. Moreover, programming in traditional methods is also very time-consuming. The time needed to create IT software (for one operating system and device) using traditional programming is often not shorter than 6 moths and very often the time needed to create solutions running under all popular operating systems requires years of work of a team of professionals. The no-code approach allows to develop software solutions easily and quickly without the need to wait for IT professionals to complete all programming services needed [1]. It is important to note that different no-code platforms offer different functionalities which for one project the functionalities can be disadvantages and for others - very useful features. However, to make an in-depth analysis, one no-code platform (Logotec App Studio) was chosen for further investigation. Around a year and a half was spent to study the platform and its functionality. Moreover, the author used the platform to develop applications with varying functionalities.

\section{No-code Development Platform on the example of Logotec App Studio}

The subject of a study was Logotec App Studio which is a no-code development platform created by Logotec Group. The company is an application generator expert - it has been doing it for 32 years (the company received its first awards for the "Report and Application Generator" in 1986 and 1989.
At the beginning of the $21^{\text {st }}$ century, Mobile@Connector was created. It was an IT tool enabling creating IT software for mobile devices (Pocket PC at that time) completely without programming. Logotec Group with its Mobile@Connector received a number of international awards, including an award from Bill Gates in 2003 in New Orleans for the best tool for creating mobile applications [19]. Unfortunately, in 2010, Microsoft has stopped the development of Pocket PC and despite many awards, the company in order to survive, had to make a technological switch. In the last few years, Logotec Group has created - using new technologies - a new IT solution - Logotec App Studio.

Unlike Mobile@Connector, Logotec App Studio enables the creation of solutions not only for mobile devices (smartphones), but for all devices (computers, tablets, smartphones) and for all popular operating systems, i.e.: Windows 10, macOS, Android, and iOS. It is a no-code platform which enables the development of "azure" database (business) applications without a line of code. With this platform, IT software is created in two orders of magnitude shorter time than with traditional methods and two orders of magnitude cheaper than with traditional methods. The platform's creators use a data first approach which means that an application is generated based on previously created tables in a relational database. Theoretically, a database can be any data source. However, currently the platform allows to choose Microsoft SQL Server, Oracle, MySQL, PostgreSQL, MariaDB. The server layer is a .NET Core, Windows or Linux (Microsoft Azure) however, the client layer runs on Windows 10 (Universal Windows Platform). Logotec App Studio is multilingual (currently available languages: English, German, Polish, and Chinese) and was prepared for translation into any other language. The application is defined once (without programming) and then, the platform (residing in the cloud) automatically generates readyto-use, fully functional, multilayer "azure" applications running all popular operating systems. The generated solution is a native not a browser application. Created applications work online as well as offline. When the Internet connection is lost, the application turns on an offline mode which allows the user to continue the work. However, when the connection is restored, all data are synchronized and uploaded to server.

\subsection{Logotec App Studio versus traditional programming approach}

Differences between traditional programming and no-code platform (Logotec App Studio) in eight categories are presented in Figure 1. The size of implementation team when using traditional programming methods requires a team of professionals. However, when no-code is used, only one person is required to create IT software.

\begin{tabular}{|c|c|c|}
\hline & Traditional approach & Logotec App Studio \\
\hline Implementation team & A team of professionals & One person \\
\hline Required competencies & $\begin{array}{l}\text { Extensive programming experience } \\
\text { (Windows } 10 \text {, Android, iOS, macOS) }\end{array}$ & $\begin{array}{l}\text { Programming skills not required } \\
\text { (e.g. business analyst) }\end{array}$ \\
\hline Development time (prototype) & $2-3$ months & $2-5$ days \\
\hline Cost (prototype) & $\gg 200$ man-days & 2-5 man-days \\
\hline $\begin{array}{l}\text { Development time (final solution) } \\
\text { (Windows 10, Android, iOS, macOS) }\end{array}$ & A few months & A few days \\
\hline $\begin{array}{l}\text { Cost (final solution) } \\
\text { (Windows } 10 \text {, Android, iOS, macOS) }\end{array}$ & $\gg 1000$ man-days & A few man-days/man-weeks \\
\hline Modification & $\begin{array}{l}\text { Difficult } \\
\text { Time-consuming } \\
\text { Expensive }\end{array}$ & $\begin{array}{l}\text { Minutes-hours } \\
\text { Designed for easy modifications }\end{array}$ \\
\hline Investment risk & $\begin{array}{l}\text { Very high } \\
\text { (among others because of the cost of the } \\
\text { prototype) }\end{array}$ & $\begin{array}{c}\text { Minimal } \\
\text { (prototypes generated ad-hoc) }\end{array}$ \\
\hline
\end{tabular}


Moreover, a team of professionals (which uses traditional programming methods) has to have an extensive programming experience for all operating systems, which is not a requirement in the case of Logotec App Studio because an application defined once works automatically on all popular operating systems (Windows 10, Android, iOS, macOS) and can be easily (without coding) modified. The time needed to develop IT solutions with no-code platform shortens from months to days.

The time needed to prepare the prototype ranges from hours to a few days. The cost of creating both the prototype and the final solution is incomparably lower than using traditional programming methods. For instance, more than 200 man-days are required to create a prototype and more than 1000 man-days are needed to create a final solution. However, when using no-code platform, only 2-5 days (in practice, sometimes only a few hours) are needed to create a minimum viable product (MVP) and a few man-days or man-weeks are needed to create a final solution. Moreover, modifications of a product developed with traditional methods are very time-consuming, expensive and difficult. However, in the case of disruptive technology, the modifications are quick and easy. The final category is investment risk which is very high when using traditional programming methods. However, there is low investment risk when discussing no-code - some no-code platform authors offer free MVP's (which are generated ad hoc) or the possibility of resigning from using the application at any time without incurring further costs. Moreover, some platforms, like Logotec App Studio, are offered in the SaaS (Software as a Service) model making investment risks even lower.

\subsection{Logotec App Studio versus traditional programming}

Finances are important factors influencing decisions on the process of digitalization. Only a small proportion of companies are able to buy dedicated software. Nevertheless, the disruption of no-code technology is that it changes the situation. Thanks to an ability to develop software without a line of code, the process becomes cheaper and less time-consuming. This opens the door to small and medium companies. Figure 2 represents the changes in cost per user of a standard solution depending on the size of the software project. Costs per user with the traditional approach grow exponentially as the number of users decreases. However, it does not concern projects implemented with no-code platforms - costs per user are incomparably low.

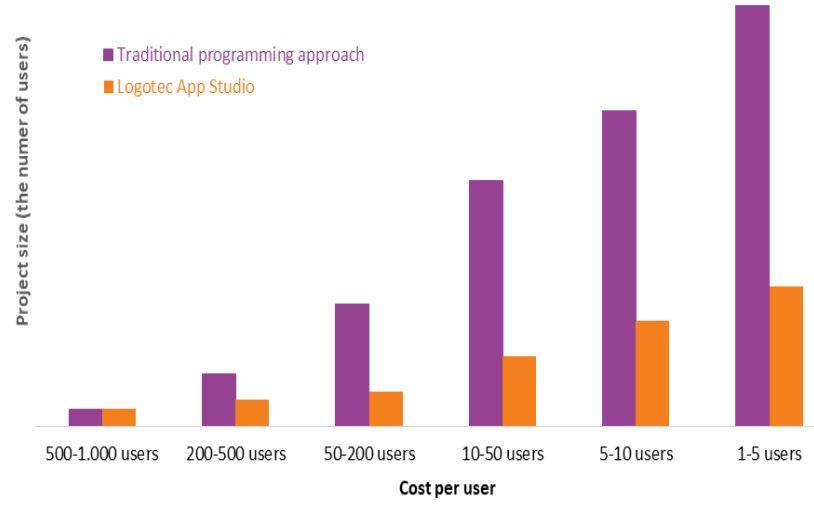

Fig. 2. Costs per user of a typical solution depending on the size of the project

The targeted software project size of traditional programming is different from the project size no-code platforms are aimed for. The traditional programming approach becomes unattractive in terms of price as the number of potential users of the solution decreases. It is attractive only when the number of users is high. However, the no-code gains the highest attractiveness in small software projects with small number of users (see Figure 3).

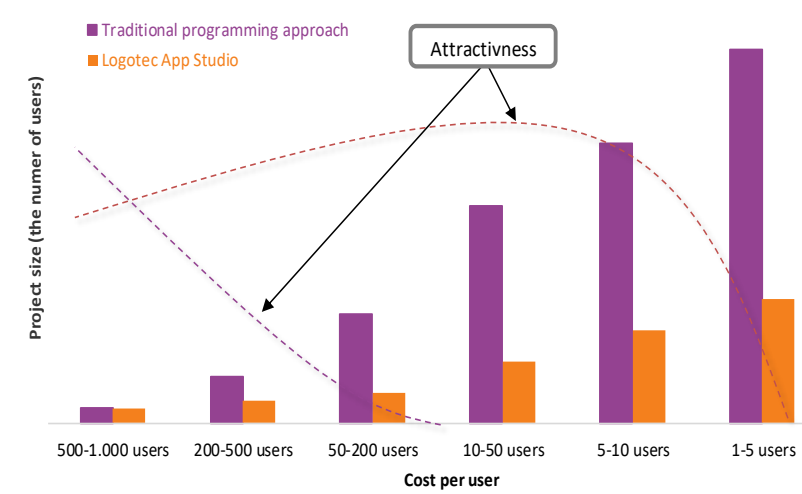

Fig. 3. The value of the solution depending on the size of the project

Small or medium software projects include dedicated software for small or medium sized companies or a specific application for companies' departments. The high costs of dedicated software allow only big companies (with more than 200 persons employed) to afford it, leaving small and medium companies without a possibility to digitalize. Nevertheless, these companies (and projects) constitute a much greater proportion of the marketplace than large enterprises employing more than 200 persons) (see Figure 4) [14]. A disruptive no-code technology resolves this problem. By providing a tool with which almost anyone can develop a native business application for all popular operating systems and devices the door to digitalization is open to those to whom it was unobtainable (due to many reasons mentioned above) before.

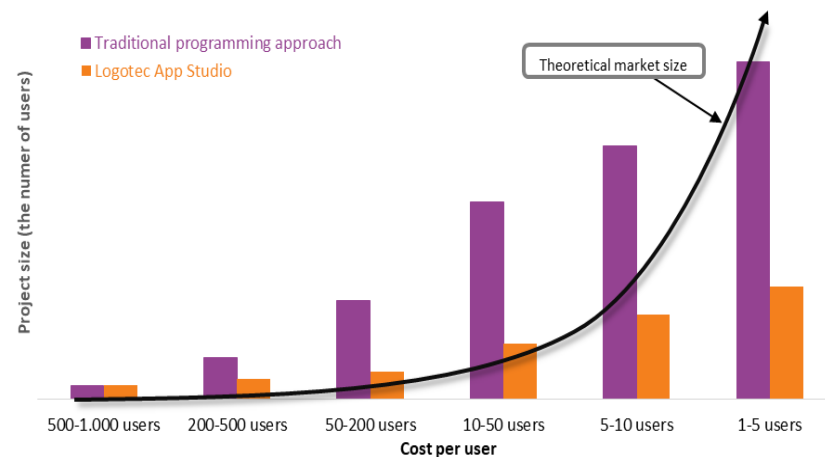

Fig. 4. Potential / theoretical size of the market

\section{No-code as a disruptive technology}

No-code and low-code are disruptive technologies gaining rising popularity. Using no-code platform, like Logotec App Studio, a person without any programming knowledge is able to develop IT software for all devices and all popular operating systems. However, professional programmers can also benefit from no-code technology. The platforms allow qualified programmers to broaden their portfolio by being able to create more projects in a shorter time without spending many months to develop a software. The costs of developing an application using no-code is cheaper and quicker than when using the traditional programming approach. There is low investment risk - some no-code platform authors, like Logotec Group, offer free MVP's or the possibility of resigning from using the application at any time without incurring further costs. Moreover, some platforms, like Logotec App Studio, are offered in the SaaS (Software as a Service) model making investment risks even lower. The changes in software developed with no-code platforms are implemented ad hoc and they can be made by anyone knowing the platform without programming knowledge. No-code platforms differ in their functionality. Some offer the development of browser solutions, the other - native applications; some require the data-first approach, preparation 
of the tables of relational database based on which an application is generated, and the others - do not require the database preparation; some platforms offer generating applications for mobile devices, while the others - for all devices and most of operating systems; some may rise data privacy concerns, while the others employs multiple data protection mechanisms, etc. Therefore, when looking for a no-code tool it is important to analyse and compare it with others' tool functionalities and features in order to choose the one which would meet one's needs.

\section{Conclusions}

The world's situation with coronavirus pandemics, contrary to the appearance, seems to be a significant opportunity for no-code technology which makes dedicated software available to the most of the companies present on the market The pandemic forces a great proportion of companies to radically lower or stop investment. Becoming even more cautious with one's decisions, increases the awareness of the labour costs and the risks associated with it. This leads to an increase in the readiness to digitalize and automate work, products and services. This digitalization in the form of introducing dedicated software gives many possibilities, for instance: enables employees to work without leaving home, prevents data loss when employees are in quarantine, etc.

The no-code technology is definitely disruptive, and soon we will see, if the Gartner's statement that "by 2024, three-quarters of large enterprises will be using at least four low-code development tools for both IT application development and citizen development initiatives" [18] will be true.

\begin{abstract}
M.Sc. Monika Moskal
e-mail:moni.moskal@outlook.com

A Ph.D. candidate at Institute of Sociology at Silesian University in Katowice and IT Business Analyst using no-code platform in creating native business database software solutions. Research interest include IT (especially no-code technology) and assimilation processes.
\end{abstract}

\section{Bibliography}

[1] Adrian B., Hinrichsen S., Nikolenko A.: App Development via Low-Code Programming as Part of Modern Industrial Engineering Education. Advances in Human Factors and Systems Interaction: Proceedings of the AHFE 2020 Virtual Conference on Human Factors and Systems Interaction. Springer Nature 2020, 45-54.

[2] Bloomber J.: The Low-Code/No-Code Movement: More Disruptive Than You Realize. Forbes [https://www.forbes.com/sites/jasonbloomberg/2017/07/20/thelow-codeno-code-movement-more-disruptive-than-you-realize/\#52be2098722a] (20 July 2017)

[3] Brennen S., Kreiss D.: Digitalization and Digitization. [http://culturedigitally.org/2014/09/digitalization-and-digitization/] (8 September 2014).

[4] Buxton J., Macro A.: The Craft of Software Engineering. Addison-Wesley, Wokingham 1987.

[5] Ciot T: What is a Low-Code/No-Code Platform? [https://devops.cioreview.com/cxoinsight/what-is-a-lowcodenocode-platformnid-15249-cid-99.html] (17 November 2020).

[6] Gartner Inc.: Gartner. [https://www.gartner.com/en/about].

[7] Han J., Pei J., Kamber M.: Data Mining: Concepts and Techniques. Morgan Kaufmann Publishers Inc., Burlington 2011.

[8] Henriette E., Mondher F., Boughzala I.: The Shape of Digital Transformation: A Systematic Literature Review. Ninth Mediterranean Conference on Information Systems (MCIS). Samos 2015.

[9] Ince D. C.: Software Engineering. Van Nostrand Reinhold, London 1989.

[10] Knuth D. E.: Algorithmic Thinking and Mathematical Thinking. The American Mathematical Monthly 92(3), 1985, 170-181.

[11] Logotec Engineering S.A. [https://logotec.pl/].

[12] Logotec Engineering S.A. [https://logotec.pl/pl/o-nas]

[13] Molyneux P.: Declarative Programming. Managing with Information Technology. Springer, London 1993.

[14] OECD: Enterprises by business size. 2021 [http://doi.org/10.1787/31d5eeaf-en]

[15] Parviainen P., Tihinen M., Kääriäinen J., Teppola S.: Tackling the digitalization challenge: how to benefit from digitalization in practice. International Journal of Information Systems and Project Management V(1), 2017, 63-77.

[16] Sommerville I.: Software Engineering. Addison-Wesley, Wokingham 1989

[17] Stolterman E., Fors A. C.: Information Technology and the Good Life. Information Systems Research: Relevant Theory and Informed Practice. Kluwer Academic Publishers, London 2004.

[18] Vincent P., Iijima K., Driver M., Wong J., Natis Y.: Gartner Magic Quadrant for Enterprise Low-Code Application Platforms. [https://www.gartner.com/en/documents/3956079/magic-quadrant-forenterprise-low-code-application-platf]. 